\title{
14. \\ Cancers attributable to occupational exposures in the UK in 2010
}

\begin{abstract}
DM Parkin*,I London, UK

(C) 20II Cancer Research UK

The International Agency for Research on Cancer (IARC, 2010a) has classified 107 agents, mixtures or exposure circumstances as Group 1 (carcinogenic to humans), many of which are encountered in occupational settings, for example, asbestos and cadmium. An additional 58 agents, mixtures or exposure circumstances have been classified as Group 2A (probably carcinogenic to humans). Those with occupational significance include diesel fumes and benzidine-based dyes (IARC, 2010a). Table 1 (adapted from Siemiatycki et al, 2004) shows the most important occupational exposures in these two categories.

A comprehensive analysis of occupational exposures, with quantitative estimates of the cancers attributable to them, has been carried out by Imperial College London and the Health and Safety Laboratory on behalf of the Health \& Safety Executive by Rushton et al (2007). This analysis has been updated and extended, based on mortality in Britain in 2005 and incidence in 2004 (Rushton et al, 2010). Here, we have applied the populationattributable fractions (PAFs) for Great Britain, as estimated in this paper, to the estimated cancer incidence in UK in 2010.
\end{abstract}

'Centre for Cancer Prevention, Wolfson Institute of Preventive Medicine, Queen Mary University of London, Charterhouse Square, London ECIM 6BQ

British Journal of Cancer (201 I) 105, S70-S72; doi:I0.1038/bjc.20II.487 www.bjcancer.com

\section{METHODS}

The methodology used to estimate PAFs of each cancer is described in the papers by Rushton et al $(2007,2010)$. The carcinogenic agents or exposure circumstances identified for each cancer were those classified by the IARC as Group 1 or $2 \mathrm{~A}$ carcinogens (IARC, 2010a). Estimation of PAFs requires data on the relative risk of each exposure, and the prevalence in the general population.

Risk estimates were obtained from key studies, meta-analyses or pooled studies, taking into account quality, such as relevance to Britain, sample size, extent of control for confounders, adequacy of exposure assessment, and clarity of case definition. Where possible, risk estimates that had been adjusted for important non-occupational confounding factors, for example, smoking status, were selected. In general, dose-response risk estimates were not available from the epidemiological literature, nor were proportions of those exposed at different levels of exposure over time available for the working population of Britain. However,

*Correspondence: Professor DM Parkin; E-mail: d.m.parkin@qmul.ac.uk where possible risk estimates were obtained for an overall 'lower' level and an overall 'higher' level of exposure to the agents of concern.

With respect to the latency between exposure and the elevated risk of cancer, a 'relevant exposure period' was defined. For solid tumours a latency of $10-50$ years was assumed; for haematopoietic neoplasms it was $0-20$ years.

The proportion of the population exposed to each carcinogenic agent or occupation was obtained from the total number of people employed and the numbers potentially exposed to the carcinogens of interest in each relevant industry/occupation within Britain. If the study from which the risk estimates were obtained was population based, an estimate of the proportion of the population exposed was derived directly from the study data. If the risk estimate was obtained from an industry-based study, national data sources, the CARcinogen EXposure (CAREX) database, the UK Labour Force Survey (LFS) or Census of Employment (CoE) was used to obtain the proportions exposed to the carcinogens concerned in Britain. Adjustment factors were applied to the data to take account of the change in numbers employed and the employment turnover during the 'relevant exposure period'.

The studies from which risk estimates were taken were often mortality studies only and PAFs derived from these were applied to numbers of registrations. The PAFs published by Rushton et al (2010) have been applied to the estimated numbers of cancers in the UK in 2010, with the following exceptions:

- We exclude occupationally induced non-melanoma skin cancers, for the reasons stated in the introduction - primarily that enumeration of such tumours is very far from complete (so that including them among the total cancers attributable to different exposures is misleading).

- PAFs due to occupational exposure to environmental tobacco smoke are included with other tobacco-related cancers in Chapter 2 (Parkin, 2011).

\section{RESULTS}

Table 2 shows the estimated number of new cancer cases in 2010 for 22 types of cancer, the PAFs (from Rushton et al, 2010) and the estimated numbers of cases due to occupational exposures. The 
Table I Occupational exposures linked to cancer risk and industries in which exposures can occur

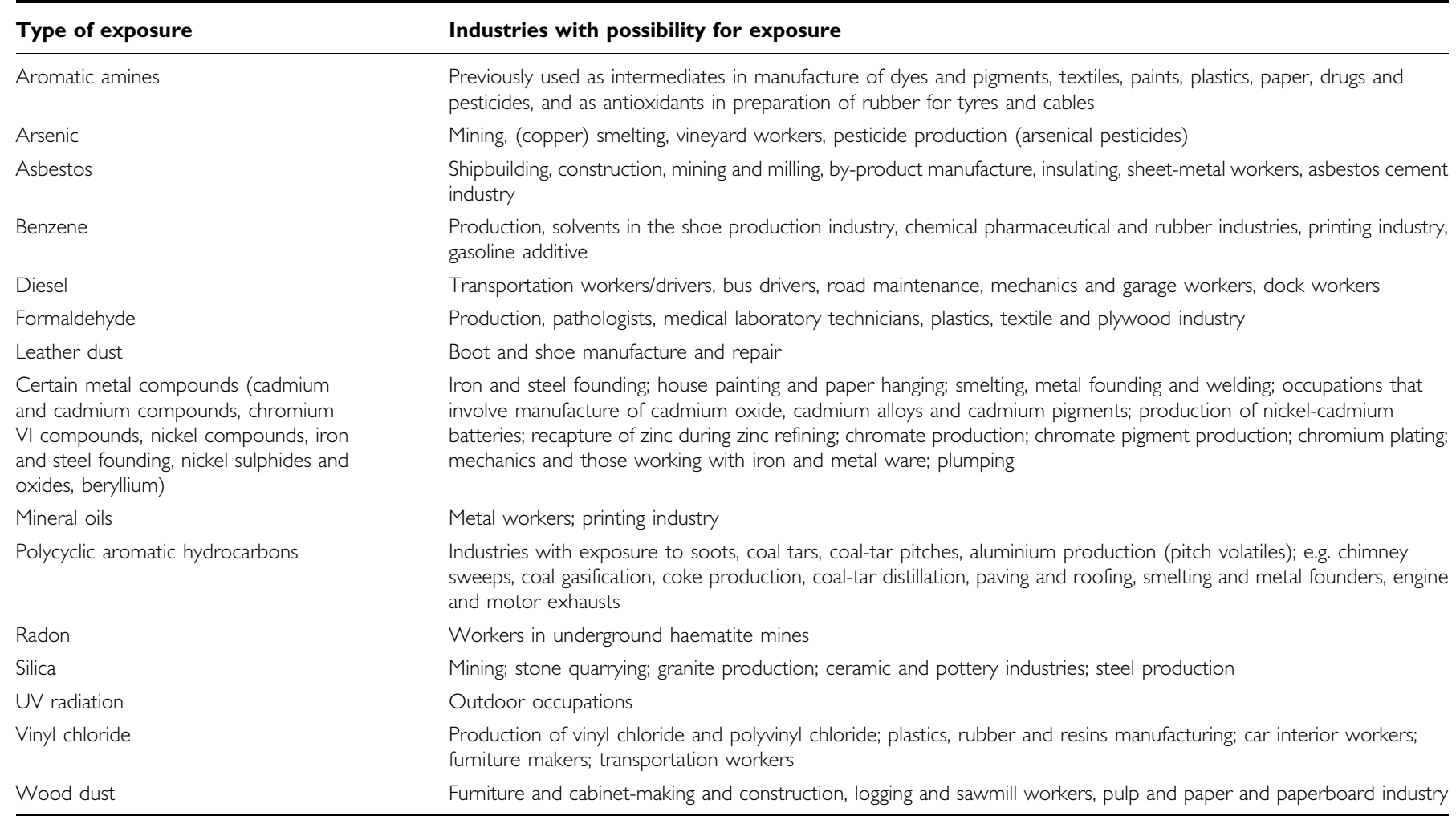

Adapted from Siemiatycki et al (2004).

Table 2 Estimated fractions of cancer cases in UK, 2010, attributable to occupational exposures

\begin{tabular}{|c|c|c|c|c|c|c|c|}
\hline Cancer site & ICD-I 0 code & \multicolumn{2}{|c|}{ Observed cases } & \multicolumn{2}{|c|}{ PAF $^{a}(\%)$} & \multicolumn{2}{|c|}{ Excess attributable cases } \\
\hline Oesophagus & $\mathrm{Cl} 5$ & 5713 & 2819 & 3.3 & 1.1 & 189 & 31 \\
\hline Stomach & $\mathrm{Cl} 6$ & 4467 & 2577 & 3 & 0.3 & 134 & 7.7 \\
\hline Liver & C22 & 2270 & 1298 & 0.2 & 0.1 & 4.5 & 1.3 \\
\hline Pancreas & C25 & 4084 & 4280 & 0.02 & 0.01 & 0.8 & 0.4 \\
\hline Lung $^{c}$ & C33 & 22273 & 18132 & 20.5 & 4.3 & 4566 & 780 \\
\hline Bone & C $40-41$ & 362 & 256 & 0.04 & 0.01 & 0.1 & 0.0 \\
\hline Mesothelioma ${ }^{\mathrm{b}}$ & C45 & 2077 & 462 & 97 & 82.5 & 2015 & 381 \\
\hline Soft-tissue sarcoma ${ }^{b}$ & C49 & 867 & 623 & 3.4 & 1.1 & 29 & 6.9 \\
\hline Breast (female) & C50 & - & 48385 & - & 4.6 & - & 2226 \\
\hline Cervix & C53 & - & 2691 & - & 0.7 & - & 19 \\
\hline Ovary & C56 & - & 6820 & - & 0.5 & - & 34 \\
\hline Non-Hodgkin lymphoma & $\mathrm{C} 82-85, \mathrm{C} 96$ & 6297 & 5305 & 2.1 & I.1 & 132 & 58 \\
\hline Myeloma & C90 & 2506 & 1994 & 0.4 & 0.1 & 10 & 2.0 \\
\hline Leukaemia & C91-95 & 4639 & 3201 & 0.9 & 0.5 & 42 & 16 \\
\hline$A l^{d}$ & & 158667 & 155584 & 4.9 & 2.4 & 7832 & 3662 \\
\hline
\end{tabular}

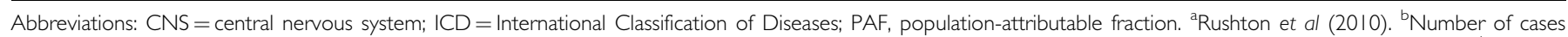
estimated from the UK population (20I0) and rates in England in 2008. 'Lung cancer PAF excludes occupational exposure to environmental tobacco smoke (ETS). ${ }^{d}$ Excluding non-melanoma skin cancer.

total is an estimated 11494 cases (7832 in men and 3662 in women), representing $3.7 \%$ of all cancers (excluding nonmelanoma skin cancers). The most substantial numbers are lung cancers (exposures due to asbestos, silica, diesel engine exhausts, mineral oils), mesotheliomas (asbestos) and breast cancer, related to shift work that involves circadian disruption (IARC, 2010b). 


\section{DISCUSSION}

Included in the evaluation of Rushton et al (2010) were non-melanoma skin cancers, the calculated PAF of which $(4.6 \%)$ was applied directly to the number of registrations in 2004. The latter may have been due to a lack of appreciation by the authors of the incomplete nature of cancer registration for non-melanoma skin cancer. Undercounting of such cancers is a consequence of the relatively trivial nature of the great majority, and many such cancers are treated without hospitalization or, probably, a biopsy. Registration is biased by cell type (basal cell cancers will certainly be undercounted), while some cancers - probably occupationally related ones - may be more completely identified.

Prevalence of exposure in the analysis by Rushton et al (2010) was estimated for a period of 10-50 years prior to 2005 for solid tumours, and 0-20 years for haematopoietic neoplasms. If exposure prevalence has been declining, and these latency periods are correct, it is possible that the numbers of attributable cancers for 2010 will be slightly overestimated (because the time since exposure is 5 years longer than for the estimates for 2005).

Several other studies have been carried out to estimate the proportion of cancers in a given population that are possibly the result of exposure to carcinogens in an occupational setting. Doll and Peto (1981) included occupational factors in their evaluation of the quantitative contribution of different factors to cancer mortality in the United States. In addition to the USA, estimates of the effect of occupational exposures on the burden of cancer have been made for the year 2000 for the populations of the Nordic countries (Dreyer et al, 1997), Australia (Fritschi and Driscoll, 2006) and France (IARC, 2007). Quantitative estimates of the carcinogenic effect of 11 occupational exposures worldwide in the year 2000 were made by Driscoll et al (2005).

These recent studies used a methodology similar to that of Rushton et al (2010) - the CAREX (CARcinogen Exposure) database - to provide national estimates of the proportions of workers exposed to different carcinogens and their levels of exposure (Finnish Institute of Occupational Health, 2009), and estimates of the relative risk of different exposures, drawn from literature reviews. There are differences not only in the choice of such studies (and hence of risks associated with occupational exposures, and different levels of exposure), but also in the precise choice of exposures, which can reasonably be considered to be carcinogenic in an occupational setting.

The Nordic study (Dreyer et al, 1997) estimated that verified industrial carcinogens will account for approximately $3 \%$ of all cancers in men and less than $0.1 \%$ of all cancers in women in the Nordic countries around the year 2000, while the French study estimated that $2.5 \%$ of cancers in men and $0.3 \%$ in women were caused by occupation.

See acknowledgements on page $\mathrm{Si}$.

\section{Conflict of interest}

The author declares no conflict of interest.

\section{REFERENCES}

Doll R, Peto R (1981) The causes of cancer: quantitative estimates of avoidable risks of cancer in the United States today. J Natl Cancer Inst 66: $1191-1308$

Dreyer L, Andersen A, Pukkala E (1997) Avoidable cancers in the Nordic countries. APMIS Suppl 76: $68-79$

Driscoll T, Nelson DI, Steenland K, Leigh J, Concha-Barrientos M, Fingerhut M, Prüss-Ustün A (2005) The global burden of disease due to occupational carcinogens. Am J Ind Med 48: 419-431

Finnish Institute of Occupational Health (2009) CAREX: International Information System on Occupational Exposure to Carcinogens. http:// www.ttl.fi/Internet/English/Organization/Collaboration/Carex/

Fritschi L, Driscoll T (2006) Cancer due to occupation in Australia. Aust N Z J Public Health 30: 213-219

International Agency for Research on Cancer (IARC) (2007) IARC Working Group Reports (3): Attributable Causes of Cancer in France in the year 2000. International Agency for Research on Cancer: Lyon, France

International Agency for Research on Cancer (IARC) (2010a) Agents Classified by the IARC Monographs, Vols. 1-100. International Agency for Research on Cancer: Lyon, France. http://monographs.iarc.fr/ENG/ Classification/index.php
International Agency for Research on Cancer (IARC) (2010b) Monographs on the Evaluation of Carcinogenic Risks to Humans: Vol. 98. Painting, Firefighting, and Shiftwork. International Agency for Research on Cancer: Lyon, France

Parkin DM (2011) Tobacco-attributable cancer burden in the UK in 2010. Br J Cancer 105(Suppl 2): S6-S13

Rushton L, Bagga S, Bevan R, Brown TP, Cherrie JW, Holmes P, Fortunato L, Slack R, Van Tongeren M, Young C, Hutchings SJ (2010) Occupation and cancer in Britain. Br J Cancer 102: 1428-1437

Rushton R, Hutchings S, Brown T (2007) Research Report 595: The Burden of Occupational Cancer in Great Britain. Prepared by Imperial College London and the Health and Safety Laboratory. Health \& Safety Executive

Siemiatycki J, Richardson L, Straif K, Latreille B, Lakhani R, Campbell S, Rousseau MC, Boffetta P (2004) Listing occupational carcinogens. Environ Health Perspect 112: $1447-1459$

cc) (9) This work is licensed under the Creative Commons Attribution-NonCommercial-Share Alike 3.0 Unported License. To view a copy of this license, visit http://creativecommons. org/licenses/by-nc-sa/3.0/ 